\title{
Techniques for evaluating the spatial behaviour of river fish
}

\author{
Kathy H. Hodder • Jerome E. G. Masters • \\ William R. C. Beaumont · Rodolphe E. Gozlan • \\ Adrian C. Pinder - Carolyn M. Knight • \\ Robert E. Kenward
}

(C) Springer Science+Business Media B.V. 2007

\begin{abstract}
Radio-tagging is widely used for studies of movements, resource use and demography of land vertebrates, with potential to combine such data for predictive modelling of populations from individuals. Such modelling requires standard measures of individual space use, for combination with data on resources, survival, dispersal and breeding. This paper describes how protocols for efficient collection of space-use data can be developed during a pilot study, and reviews the ways in which such data can be used for space-use indices that help answer biological questions, with examples from a study of riverine pike (Esox lucius). Analyses of diurnal activity and spatiotemporal correlation were used to assess when to record locations, and analyses of home range
\end{abstract}

Guest editors: P. R. Almeida, B. R. Quintella, M. J. Costa and A. Moore

Developments in Fish Telemetry

K. H. Hodder $(\bowtie) \cdot$ J. E. G. Masters ·

W. R. C. Beaumont - R. E. Gozlan - A. C. Pinder ·

C. M. Knight · R. E. Kenward

Centre for Ecology and Hydrology, Winfrith

Technology Centre, Winfrith Newburgh, Dorchester,

Dorset DT2 8ZD, UK

e-mail: khh@ceh.ac.uk

C. M. Knight

School of Biological and Biomedical Sciences, Science

Laboratories, University of Durham, South Road,

Durham DH1 3LE, UK increments were used to define the number of location records necessary to assess seasonal ranges. We stress the importance of developing protocols that use minimal numbers of locations from each individual, so that analyses can be based on samples of many individuals. The efficacy of link-distance (e.g. cluster analysis) and location density (e.g. contouring) techniques for spatial analysis for river fish were compared, and the utility of clipping off areas to river banks was assessed. In addition, a new automated analysis was used to estimate distances along river midlines. These techniques made it possible to quantify interactions between individuals and their habitat: including a significant increase in core range size during floods, significant preference for deep pools, and a lack of exclusive territories.

Keywords Home range - Core range · Radio-tracking $\cdot$ Cluster polygon · Pike

\section{Introduction}

Radio tagging has been used in the study of home ranges of river fish for several decades, but there is little guidance available for efficient data collection and analysis in the lotic environment. At the outset of a project to study spatial behaviour, decisions need to be made about the sample size of fish, the number of locations to 
record for each individual, the timing of recording and the time interval between location records. In this paper, we show how initial tracking sessions can be designed as a pilot study in order to determine a tracking protocol appropriate for providing answers to the biological questions of interest. The pilot study can determine the number of location records required to describe a stable home range, an issue that has rarely been addressed in studies of river fish (exceptions are Natsumeda, 1998; Snedden et al., 1999). It can also be used to establish the optimal sampling interval (Lucas \& Batley, 1996; Baras, 1998; Ovidio et al., 2000), in part by determining the degree of autocorrelation between location records (Chapman \& Mackay, 1984). Here we approach these issues with a number of methods including application of the test of Time To Independence (TTI) of locations (Swihart \& Slade, 1985) to river fish for the first time.

In spatial analyses of river fish behaviour, the home range has often been defined using the range span, measured between maximal upstream and downstream locations, and expressing range area as the longitudinal displacement multiplied by mean stream width (Minns, 1996; Huber \& Kirchhofer, 1998; Vokoun, 2003). This approach gives a good indication of the overall area available to the fish, but oversimplifies understanding of space use. The total area used may be disproportionately influenced by the inclusion of just one excursive location and greatly overestimate the smaller areas that are favoured by fish, as by other animals, for most of their activities. This overestimation of space use has the potential to give spurious or misleading results in assessments of habitat association or of predatory and social interaction between individuals. More detailed techniques for analysis of range structure have been developed in studies of terrestrial animals (White \& Garrot, 1990; Kenward, 2001), such as contouring methods (Dixon \& Chapman, 1980; Worton, 1987, 1989) and cluster polygons (Kenward, 1987). These methods describe internal range structure by excluding outlying locations to give a core range, which may have one or more nuclei (activity centres). This paper explores the utility of these methods for analysing the ranges of river fish using location data for northern pike
Esox lucius (L.). Can these methods, originally designed for studying animals in non-linear environments, adequately represent the size, shape and structure of home ranges in rivers?

\section{Materials and methods}

\section{Study site}

Pike were tracked in the River Frome, a chalk stream in Dorset, UK. The study area (NGR 367863,382870 ) included a $2 \mathrm{~km}$ stretch of the main channel with a mean $( \pm \mathrm{se})$ stream width of $14.2( \pm 0.6) \mathrm{m}$, a millstream $(1.2 \mathrm{~km})$, and artificial ditches (Fig. 1). It was selected on the basis of a pilot study (see below) to give the optimum tradeoff between practical constraints (terrain, available trackers, distance between tagged fish) and aims (i) to maximise the sample size of individual fish while (ii) also representing different channel characteristics (straight and meandering). The latter aim provided the potential to test how home range estimators functioned in different linear environments. A weir formed a potential barrier (depending on water levels) at the upstream limit, whereas there were no barriers to fish movement at the downstream limit. The ditches were seasonally inundated, and adjacent water meadows were flooded during one of two winter seasons. Streambed topography was mapped along $1108 \mathrm{~m}$ of the main channel by measuring depths on transects at $5 \mathrm{~m}$ intervals along the channel, and at $2 \mathrm{~m}$ intervals across it.

Radio tagging and tracking

Twenty-seven pike with a mean fork length of $69 \mathrm{~cm}$ (range 52-95 cm) were implanted with Biotrack TW-5 radio tags (length $8 \mathrm{~cm}$, diameter $1.6 \mathrm{~cm}$, weight $22 \mathrm{~g}$ in air, $7 \mathrm{~g}$ in water), released into the river and allowed 10 days to recover prior to the commencement of data collection (Beaumont et al., 2002; Jepsen et al., 2000). Location records for the pike were determined from the riverbank, using Yaesu FT290 receivers and 3 element Yagi antennae, by triangulation and detuning the radio receiver. Blind experiments with tags in known positions indicated that a location resolution of 1$2 \mathrm{~m}^{2}$ could be achieved with this method. 
Fig. 1 The extent of area that was available to pike in the study area on the River Frome, at three different water levels

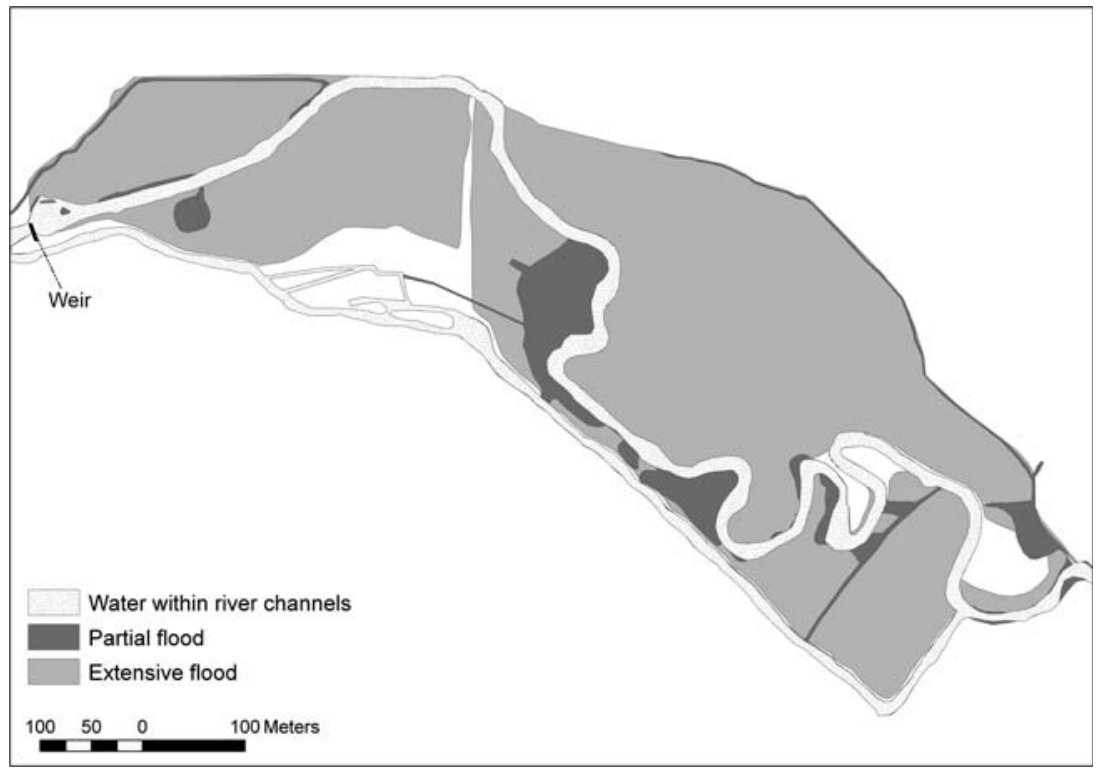

Development of tracking protocol

The protocol for estimation of pike home ranges was developed through a pilot tracking study at the very start of the project. Whilst in theory the greater the number of fish tracked in a pilot study, the greater the confidence in the results, the practicalities of capturing the fish and tracking them at short time intervals resulted in pilot data being available for only the first two pike tagged (body lengths $86 \mathrm{~cm}$ (A) and $71 \mathrm{~cm}(\mathrm{~B}))$. Location data for these fish were recorded in a $300 \mathrm{~m}$ stretch of river at hourly intervals over five consecutive 24 -h periods in June 2000. The aim was to determine the minimum number of location records required to estimate a home range, the optimum sampling interval, and the most appropriate time(s) of day for sampling. A minimum number of locations was required to allow simultaneous tracking of as many individuals as possible, and also estimation of ranges within relatively short time periods, avoiding range shifts following events such as floods (Masters et al., 2002), or seasonal migrations such as spawning.

\section{Sampling interval for location records}

Locations that are recorded every minute, for a fish that moves at $10 \mathrm{~m}$ a minute, would not be expected to be more than $10 \mathrm{~m}$ apart after the first minute, $20 \mathrm{~m}$ after the second minute etc. In other words they are spatio-temporally correlated. However, when animals move back and forth through their ranges, eventually a time interval will be reached when the first location cannot predict where the second will be; this is the TTI. A method for determining TTI between consecutive locations was developed by Swihart \& Slade (1985). The procedure examines the way that the distance between location records changes with sampling intervals using Schoener's index, $V=t^{2} / r^{2}$, where $t^{2}$ is the mean squared distance between consecutive location records and $r^{2}$ is the mean squared distance from each location to the range centre (the arithmetic mean of all coordinates). TTI between locations is indicated when the first of three successive time intervals exceed $V=2$. This is roughly equivalent to the time required for an animal to traverse its whole range (Swihart \& Slade, 1985). In practice the time required to traverse half the range width $(V=1)$ may be more useful (Kenward, 2001) so the outcomes of using both $V=1$ and $V=2$ were examined for the pilot tracking data.

\section{Diel activity patterns}

Many animals timetable their activities; for example, they may roost in one place and move to 
forage in another during each day (e.g. Clough \& Ladle, 1997). Such habitual behaviour may be indicated in autocorrelation analysis (see above). If an animal tended to be in the same place at the same time each day, serial correlation of its locations would be expected to peak at about $24 \mathrm{~h}$. In order to design a tracking protocol that would adequately represent the locations used by the fish, more detailed information was required about levels of activity at different times of day. Distances between consecutive location records were used to investigate whether the mobility of the two pike varied on a diel basis and provide guidance on the most appropriate times of day to track the pike. The diel period was split into dawn, day, dusk and night for the analysis; crepuscular periods were defined as dawn, $1 \mathrm{~h}$ before and $2 \mathrm{~h}$ after sunrise, and dusk, $2 \mathrm{~h}$ before and $1 \mathrm{~h}$ after sunset. The hours before sunrise and after sunset were included so that first and last light would fall within the crepuscular period.

\section{The number of location records required}

It is always necessary to balance the need for sufficient locations for each individual with the need to collect data on an adequate sample of animals. So to give time for data collection on enough individuals, it is useful to estimate the minimum number of location records that are required to calculate stable home ranges for individuals in the study population. In other words, within a predefined time period (e.g. season) when does the range area cease to increase as further location records are added? The change in range area with addition of successive fixes was determined for the two original pike plus one other pike that was tagged part way through the pilot study. The channel used by the three pike was relatively straight, so it was possible to use the outer minimum convex polygon (Mohr, 1947) to delineate the ranges in this analysis without excessive expansion of the range outside of the channel (see discussion on 'clipping' range areas below).

Estimation of pike home ranges

Definition of a home range has progressed from an area traversed during the 'normal' activities of an animal (Burt, 1943) to a concept that refers to an area repeatedly traversed within a specific period of time (Kenward, 2001; Kernohan et al., 2001). This was described by Doncaster \& Macdonald (1991) as the 'prevailing range', which may shift with season, life history, environmental or demographic changes. Delineation of this short-term range enables quantitative comparisons between animal categories, and investigation of habitat utilisation and interactions, both intraand interspecific (depending on the animals tagged). There are numerous statistical techniques available for home range analysis, which can provide estimates not only of the total area used but also the structure, in terms of core and excursive areas, and the range shape. Realistic representation of the home range shape is important if spatial coincidence with habitat features or other individuals is of interest. Detailed discussion of home range estimators and their suitability for different types of data or study question are reviewed by Kenward $(1992,2001)$ and White \& Garrot (1990). In this study, a sample of the most promising methods were investigated to determine their efficacy for analysis of animal locations in a linear environment, and also for comparison between seasons for a river that habitually floods-leading to a less restricted available area for the fish. Home ranges estimated by the distance (or area) between furthest upstream and downstream locations were compared with ranges estimated with cluster polygons and by a kernel contouring method.

A home range tracking protocol was finalised using the data collected during the pilot track (see results) and eight tracking sessions were conducted between July 2000 and March 2002 (Table 1). Over this period, sufficient data were collected on 20 pike to investigate the extent and structure of 68 seasonal ranges.

\section{Outer ranges}

The total, or outer, home ranges were assessed using two linear techniques and one contouring method:

(i) a linear range span-the distance along the midline of the channel between the maximal 
Table 1 Dates and flow conditions of the radio-tracking sessions used to establish pike home ranges

\begin{tabular}{lcl}
\hline Date & N pike & Flow conditions \\
\hline July 2000 & 3 & Within the channel \\
September 2000 & 3 & Within the channel \\
December 2000 & 5 & Extensive flood \\
March 2001 & 10 & Partial flood \\
July 2001 & 9 & Within the channel \\
September 2001 & 12 & Within the channel \\
December 2001 & 12 & Within the channel \\
March 2002 & 14 & Within the channel \\
\hline
\end{tabular}

upstream and downstream location records was estimated using a modified version of RANGES V (Kenward \& Hodder, 1996). The area of the channel between these two locations (range span area, see Fig. 2), was also calculated from maps. There were slight variations in channel width in the study area; therefore this method was more accurate than multiplying the range span by mean channel width. The range span measure can provide results that are comparable with linear home ranges from other studies e.g. (Huber \& Kirchhofer, 1998; Ovidio et al., 2002; Khan et al., 2004), and the range span area gives a measure more comparable with the home range areas derived from outlines based on contours or polygons. (ii) Kernel contours (Worton, 1989) were selected for estimating outer ranges from the density distribution of locations; this approach has previously been applied to linear ranges by (Blundell et al., 2001). The $\mathrm{K}_{100}$ contour was used; this just includes all the locations, differing from the minimum convex polygon (Mohr, 1947) in that it can identify separate activity nuclei.

Kernel contours $\left(\mathrm{K}_{100}\right)$ that used the default reference smoothing parameter tended to expand beyond the river channel (Fig. 2); therefore, the areas were corrected by clipping off regions outside of the river (Mesing \& Wicker, 1986; Allouche et al., 1999). Three maps were required for this purpose, delineating different water levels during the study: within-channel, partial flood and extensive flood (Fig. 1). These three boundary maps were used to clip off parts of the range area of the $\mathrm{K}_{100}$ estimator, which made it possible to compare ranges at the different water levels, whereas the range span could only be calculated when the river was within its banks.

The expansion of the kernel ranges beyond the channel made it inevitable that area estimates during floods would be larger than those recorded in lower water conditions, even if fish locations
Fig. 2 Home range estimates for two pike ( $E$. lucius) $\mathbf{J}(\boldsymbol{\square})$ and $\mathrm{P}(\boldsymbol{\Delta})$ (fork lengths $93 \mathrm{~cm}$ and $58 \mathrm{~cm}$ respectively). Shaded areas represent the range span between the upstream and downstream limits; the outer contours show the $\mathrm{K}_{100}$ range edges; and the bold lines the $\mathrm{C}_{\mathrm{tx}}$ range edges

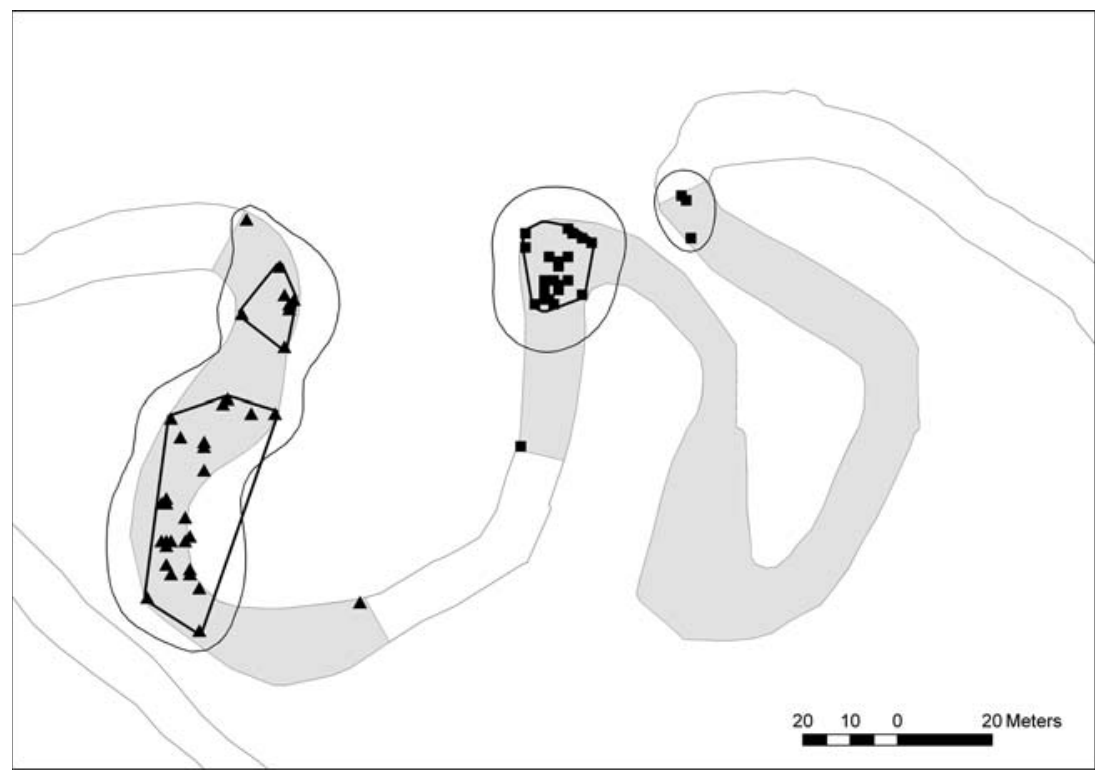


were identical at the two water levels. In order to check for Type I statistical errors associated with this problem, range areas were estimated for 'in channel' conditions using both within-channel and extensive flood maps (Fig. 1).

\section{Core ranges}

Convex cluster polygons (Kenward, 1987) were used to investigate core areas of intensive use. The polygons are estimated round clusters of locations that represent an ascending sum of nearest-neighbour link distances. Core areas $\left(\mathrm{C}_{\mathrm{tx}}\right)$ were estimated separately for each range, by excluding outlying location records through truncation of the upper $5 \%$ of the nearest neighbour distance distribution (Hodder et al., 1998; Kenward et al., 2001). Generally, only small areas of the cluster polygons expanded beyond the river channel (Fig. 2), these areas were removed by clipping, as for the $\mathrm{K}_{100}$ ranges. The core range estimates were also tested for methodological bias relating to the effects of using the three different channel boundaries when clipping off parts that expanded beyond the river.

In addition to estimation of core areas, the $\mathrm{C}_{\mathrm{tx}}$ ranges indicated the degree of home range fragmentation by the number of separate nuclei in each core range, and also by a partial area index. This index divides the areas in all the cluster polygons by the area in a single polygon round all the clusters, and therefore tends to zero, if the nuclei are far apart, and to one if all the locations are in one nucleus (Kenward et al., 2001). As the calculation of $C_{t x}$ was unique for each range, the number of location records included in the core could vary. Many radiotracking studies employ a standard core for all ranges, which ensures that the same percentage of locations is used for each range (Hodder et al., 1998). However, the standard core will overestimate core areas for ranges with unusually low percentages of locations in the $\mathrm{C}_{\mathrm{tx}}$ range. This is particularly likely to cause problems when statistical comparisons with small sample sizes are required; therefore, the unique $\mathrm{C}_{\mathrm{tx}}$ cores, and not standard cores are presented here.
Range overlap

The degree of spatial interaction between fish during each tracking session was addressed by measuring the percentage area of each pike's range $\left(\mathrm{C}_{\mathrm{tx}}, \mathrm{K}_{100}\right.$ and Range Span) overlapped by other pike, and by counting the number of pike whose ranges overlapped each individual. Overlays of ranges were performed on range outlines that had been clipped.

Spatial analyses

Estimation of spatio-temporal correlation, home range outlines and their incremental increase with addition of locations used RANGES V (Kenward \& Hodder, 1996). Estimation of range span, the clipping of range outlines and their overlap initially used ArcInfo 8.1 (ESRI, Redlands, USA) but is now implemented in RANGES 6 (Anatrack, Wareham BH20 5AX, UK). All statistical tests were performed with Minitab 13, and all $t$-tests were conducted with degrees of freedom adjusted for differing sample variances. In statistical comparisons (e.g. of range area in different flow conditions), the pike, and not the range, was use as the sample unit. Where necessary average values were found from multiple ranges for the same individual.

\section{Results}

Development of the tracking protocol

\section{Sampling interval for location records}

The autocorrelation analysis provided information about TTI between consecutive locations, and also timetabling of daily activities. When values of Schoener's Index (V) were required to exceed two (equivalent to traversing the range span), TTI between consecutive locations was $11 \mathrm{~h}$ for pike $\mathrm{A}$ and $6 \mathrm{~h}$ for pike $\mathrm{B}$. When $\mathrm{V}$ was required to exceed one (equivalent to crossing half the range span), TTI was $4 \mathrm{~h}$ for pike $\mathrm{A}$ and $3 \mathrm{~h}$ for pike B (Fig. 3). The autocorrelation plots (Fig. 3) of the two fish also indicated that spatial 
Fig. 3 Autocorrelation analysis of location data for two pike (a, b).

Vertical lines indicate the Time To Independence (TTI) as the first of three consecutive points that exceed the critical value of Schoener's Index (V), set as $V=1$ or $V=2$
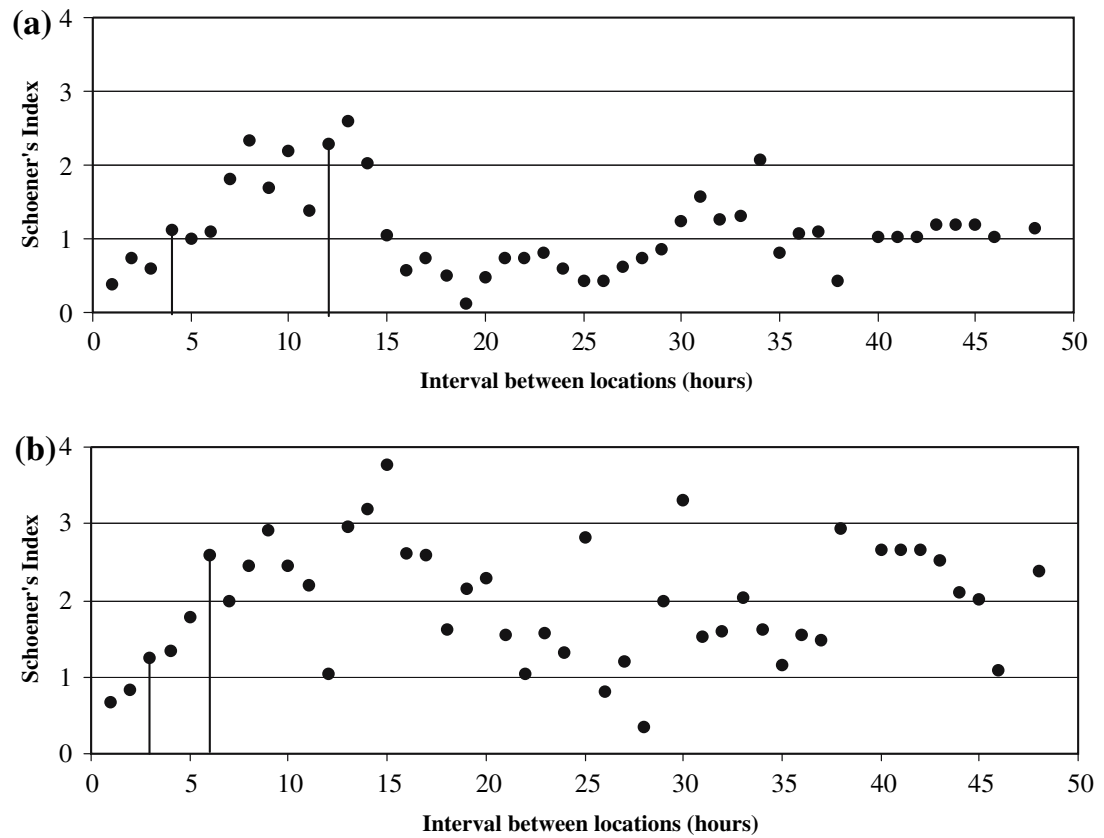

dependence of the location records may be related to diel behaviour patterns: $\mathrm{V}$ was greatest at an interval of about $15 \mathrm{~h}$ between fixes. However, at intervals of 20-25 h the value of $\mathrm{V}$ became very small again, indicating that fixes at this time interval were spatially close. Therefore, one record a day, taken at the same time, would be unlikely to describe the whole range of the fish.

\section{Diel activity patterns}

A Kruskal-Wallis test using distances between consecutive locations showed that there were significant differences between the levels of mobility recorded in the four stages of the diurnal cycle $(H=20.6$, d.f. $=3, P<0.001)$. The pike moved about more during crepuscular periods than during the day and night. Median distances moved were $13 \mathrm{~m}(\mathrm{Q} 1-3=1-37)$ at dawn and $13 \mathrm{~m}(\mathrm{Q} 1-3=0-12)$ at dusk, compared with $4 \mathrm{~m}$ (Q1-3 = 3-33) during the day, and $1 \mathrm{~m}$ (Q1$3=0-9$ ) at night. It was therefore important to schedule tracking so that a good proportion of locations would be recorded during the active periods. During the summer months in temperate latitudes, tracking during normal office hours would underestimate the mobility of this species, and also the area used.

\section{The number of location records required}

After the 5-day pilot track, although 120 fixes had been collected for each fish, incremental analysis showed that their range areas were still increasing, suggesting that data sampling should be extended over a longer period. Additional locations were recorded three times a day: at dawn, midday and dusk. This provided records at the periods of greatest mobility, and also gave the maximum sampling interval possible during daylight hours (approximately $6 \mathrm{~h}$ ) to minimise the spatial dependence between records. A second incremental analysis for three pike (A and B plus $\mathrm{C}$ ), with locations from the initial hourly tracking sub-sampled to the same three times a day, showed that the range size stabilised after around 40 location records collected over a period of 13 days (Fig. 4).

\section{Finalising the tracking protocol}

For this study, three location records a day kept spatial autocorrelation to a minimum, allowed records to be made during the most active times of day and ensured that adequate data for a stable home range should be attainable after 13 days tracking (39 locations for each fish). This 
Fig. 4 Incremental analysis of the percentage of the maximum range area (outer minimum convex polygon) against consecutive locations for three pike (E. lucius)

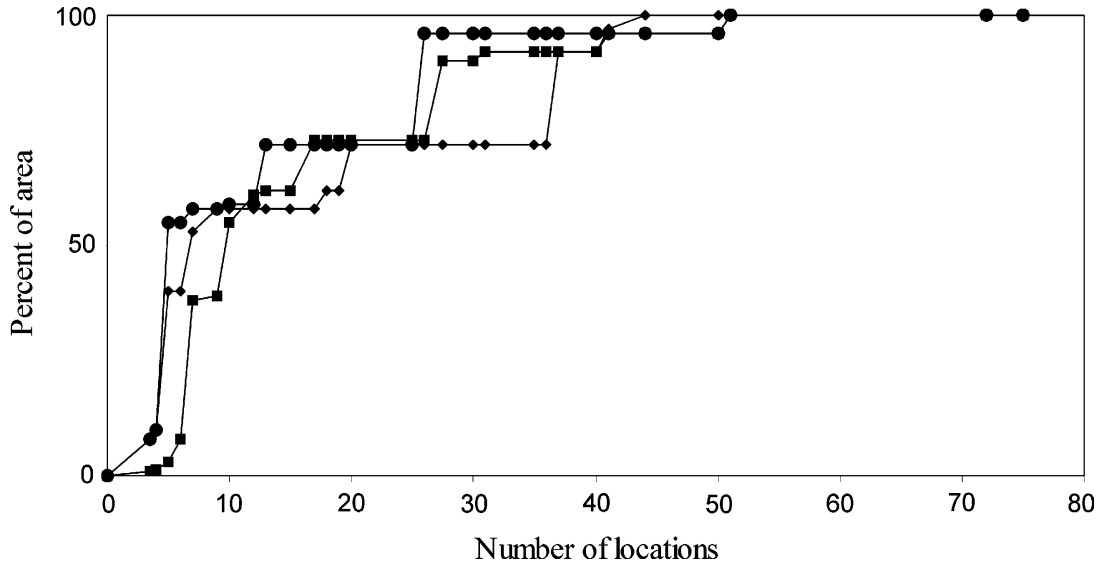

maximised the opportunity to complete tracking sessions during short-term events such as floods.

Structure of pike home ranges

Data collected during the eight tracking sessions, using the protocol described above, showed that there were considerable differences between the core $\left(\mathrm{C}_{\mathrm{tx}}\right)$ and outer range (Range Span, $\left.\mathrm{K}_{100}\right)$ areas (Table 2, Fig. 2). This indicated that the pike concentrated their activity in range cores, with occasional forays to locations that could be a great distance from the core.

This range structure was found in 65 of the 68 ranges, but three ranges, for two pike, had a smaller proportion of locations in the core, indicating greater mobility (Fig. 5). Excluding these three mobile ranges, a mean $( \pm \mathrm{se})$ of $90 \%$ $( \pm 0.5)$ of location records were included in the core ranges.

The core areas tended to be located around pools in the channel. Streambed topography data was available for 16 ranges recorded for nine pike, and areas defined by the $\mathrm{C}_{\mathrm{tx}}$ ranges for this sample were significantly deeper (mean \pm se $16 \pm 5 \mathrm{~cm}$ difference) than the area in the range span (paired $t=3.35, n=9, P=0.01$ ).

\section{Range fragmentation}

The internal structure of the pike home ranges was investigated with the $\mathrm{C}_{\mathrm{tx}}$ core ranges. These are represented by multiple nuclei where there is

Table 2 Range areas $\left(\mathrm{m}^{2}\right)$ and span distance $(\mathrm{m})$ for pike in the River Frome during different water levels

\begin{tabular}{|c|c|c|c|c|c|c|c|c|c|c|c|c|}
\hline \multirow[t]{2}{*}{ Water level } & \multirow[t]{2}{*}{ Range estimator } & \multirow[t]{2}{*}{$\mathrm{N}$ pike } & \multirow[t]{2}{*}{$\mathrm{N}$ ranges } & \multirow[t]{2}{*}{ Median } & \multirow[t]{2}{*}{ Min } & \multirow[t]{2}{*}{ Max } & \multicolumn{3}{|c|}{ Number of nuclei } & \multicolumn{3}{|c|}{ Partial area index } \\
\hline & & & & & & & Median & Min & Max & Median & Min & Max \\
\hline Within- & $\mathrm{C}_{\mathrm{tx}}$ & 19 & 53 & 515 & 51 & 3,000 & 2 & 1 & 6 & 0.40 & 0.05 & 1.00 \\
\hline \multirow[t]{3}{*}{ Channel } & $\mathrm{K}_{100}$ & 19 & 53 & 2769 & 127 & 14,602 & & & & & & \\
\hline & Range span area & 19 & 53 & 2580 & 171 & 11,231 & & & & & & \\
\hline & Range span & 19 & 53 & 205 & 15 & 899 & & & & & & \\
\hline Partial & $\mathrm{C}_{\mathrm{tx}}$ & 10 & 10 & 636 & 89 & 1,440 & 3 & 1 & 5 & 0.13 & 0.01 & 1.00 \\
\hline Flood & $\mathrm{K}_{100}$ & 10 & 10 & 6499 & 631 & 31,523 & & & & & & \\
\hline Extensive & $\mathrm{C}_{\mathrm{tx}}$ & 5 & 5 & 6174 & 346 & 8,318 & 3 & 2 & 4 & 0.26 & 0.04 & 0.56 \\
\hline Flood & $\mathrm{K}_{100}$ & 5 & 5 & 43012 & 14,452 & 63,646 & & & & & & \\
\hline
\end{tabular}

Range estimators included convex cluster polygons with outlier exclusion by truncation $\left(\mathrm{C}_{\mathrm{tx}}\right)$, kernel contours around all of the locations $\left(\mathrm{K}_{100}\right)$, and the area of channel between the maximum upstream and downstream locations (Range Span). Range fragmentation statistics are given for core ranges estimated by convex cluster polygons $\left(\mathrm{C}_{\mathrm{tx}}\right)$. A partial area index value of one indicates a single nucleus, with the value becoming smaller as multiple nuclei are more widely separated 


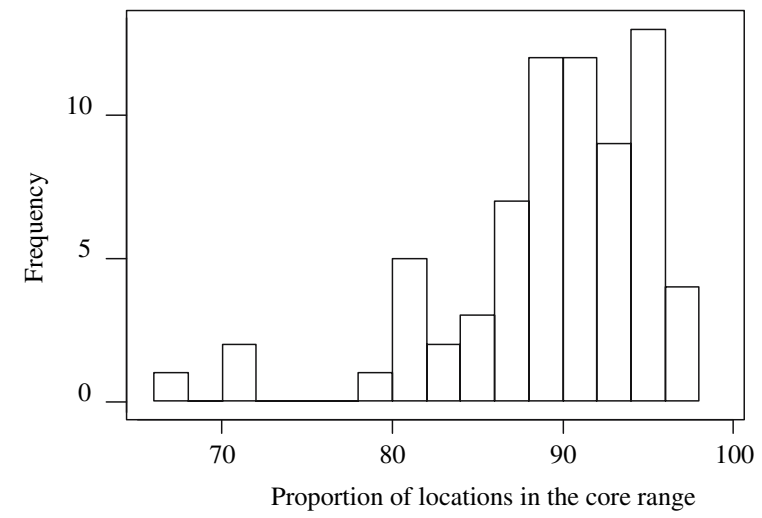

Fig. 5 The proportion of location records remaining in the $\mathrm{C}_{\mathrm{tx}}$ cores of 68 pike ranges after removal of outlying locations

more than one area of intensive use in the range (Fig. 2). Whilst $\mathrm{C}_{\mathrm{tx}}$ ranges had a median of two activity nuclei, there was great variation in the results (Table 2 ). Of the 53 ranges recorded when the river was not flooded, 11 were mononuclear, but all others had several nuclei. A wide range of partial area indices, including small values that indicated wide dispersion of nuclei, was recorded at all water levels (Table 2). When the water was within the channel, the activity centres for a single range were separated by up to $520 \mathrm{~m}$. The maximum number of $\mathrm{C}_{\mathrm{tx}}$ nuclei (6) was recorded when the water remained within the channel, however the sample size of ranges was far greater than at other times, and $t$-tests indicated that there were no significant differences in fragmentation between ranges recorded at different water levels $(P>0.05)$.

\section{Area of home ranges}

The area of the outer home ranges was best estimated for ranges within the channel by the range span. Although the $\mathrm{K}_{100}$ contours conformed well to some ranges (for instance Pike $P$, Fig. 2), in other cases, particularly in meandering stretches of river, large parts of the overall range were excluded (for instance Pike J, Fig. 2). The extension of $\mathrm{K}_{100}$ range edges beyond the channel was also problematic. The $\mathrm{K}_{100}$ area estimates for within-channel conditions were significantly larger when the map for the extensive flood was used to clip the range boundaries $(t=4.5, n=59$, $P<0.001)$. To avoid this methodological bias, the comparison of range areas at different water levels was repeated using the river outlines during the extensive flood for all ranges $\left(\mathrm{K}_{100 \mathrm{a}}\right.$ Table 3$)$. This adjustment overestimated the range areas for within-channel conditions, but ensured that any significant increase in range area during the floods would not be due to the effects of clipping. There was generally only minimal extension of $\mathrm{C}_{\mathrm{tx}}$ ranges beyond the river channel, and $t$-tests indicated there was no significant increase in range area due to methodological bias.

\section{Environmental influences on range area}

Both core $\left(\mathrm{C}_{\mathrm{tx}}\right)$ and outer $\left(\mathrm{K}_{100}\right)$ range areas were greatest during extensive flooding: the range areas of 12 pike in December, in within-channel conditions, were significantly smaller than the ranges of five pike recorded during extensive floods the previous December (Table 3). Although the median ranges during partial flooding were larger than the within-channel ranges (Table 2), there were no significant differences (Table 3). During the six tracks carried out when the water remained within the channel, discharge (recorded at the weir, Fig. 1) varied between 2 and $5.3 \mathrm{~m}^{3} \mathrm{~s}^{-1}$, with an associated $20 \mathrm{~cm}$ difference in river height, but there were no correlations between discharge and range areas $(r<0.75, P>0.08)$.

Table 3 Comparison of range areas estimated at different water levels

\begin{tabular}{llrrr}
\hline & $\begin{array}{l}\text { Range } \\
\text { estimator }\end{array}$ & d.f. $t$ & $P$ \\
\hline In channel vs. extensive & $\mathrm{C}_{\mathrm{tx}}$ & 4 & 2.9 & 0.04 \\
flood & $\mathrm{K}_{100}$ & 4 & 4.4 & 0.01 \\
& $\mathrm{~K}_{100 \mathrm{a}}$ & 8 & 2.2 & 0.05 \\
In channel vs. partial flood & $\mathrm{C}_{\mathrm{tx}}$ & 21 & -0.5 & $\mathrm{NS}$ \\
& $\mathrm{K}_{100}$ & 11 & 1.5 & $\mathrm{NS}$ \\
\hline
\end{tabular}

Areas were estimated with convex cluster polygons $\left(\mathrm{C}_{\mathrm{tx}}\right)$, kernel contours $\left(\mathrm{K}_{100}\right)$, and kernel contours allowing for bias $\left(\mathrm{K}_{100 \mathrm{a}}\right.$ where the extensive flood boundary was used for estimates at the two water levels) The degrees of freedom in $t$-tests were adjusted to differing variances between samples 


\section{Individual variation}

During the 20-month study period there was considerable variation between the range areas recorded for individual pike. This variation was found even when the data considered were limited to similar (i.e. within-channel) conditions. Data from nine pike, which all had at least four separate range estimates, showed that the variation between ranges collected for the same individual was very high in the outer ranges (mean CV ( \pm se) for nine pike: $\mathrm{K}_{100}=71 \%( \pm 8)$, Range Span $=61 \%( \pm 7))$. The mean differences between largest and smallest outer range areas for a single pike was $5,193 \mathrm{~m}^{2}$ (Range Span) and $5,998 \mathrm{~m}^{2}\left(\mathrm{~K}_{100}\right)$, and the maximum difference was $9,429 \mathrm{~m}^{2}$ (Range Span) 10,039 $\mathrm{m}^{2}\left(\mathrm{~K}_{100}\right)$. The $\mathrm{C}_{\mathrm{tx}}$ core range areas were also variable; (mean $\mathrm{CV}$ $( \pm \mathrm{se})$ for nine pike $55 \%( \pm 5))$ with a maximum difference between largest and smallest areas for a single pike of $1,301 \mathrm{~m}^{2}$.

\section{Range overlap}

There was a high degree of overlap, often with the entire outer range overlapped by other pike (Table 4). The median percentage overlap was smaller for the core ranges, but even these were sometimes completely overlapped. Medians of two or three pike overlapped their outer ranges, and there was a median of one overlap in the cores, but up to five other individuals could be found within an individual's $\mathrm{C}_{\mathrm{tx}}$ core range (Table 4). The results were not suitable for analysis of seasonal differences in overlap, or variations related to river discharge, because different numbers of pike (3-14), at different distances apart, were tracked during the eight sessions. The results are also likely to underestimate the degree of overlap between the fish because other non-tagged pike may have been present. However, it was possible to demonstrate that areas where more $\mathrm{C}_{\mathrm{tx}}$ ranges overlapped tended to be deeper (Pearson's correlation, $r=0.99$, d.f. $=3, P<0.01$, Fig. 6). It was relatively unusual for the core ranges of more than two fish to overlap in the same position (Fig. 6), but the relationship was still significant when the highest overlap value (4 core ranges overlapping),
Table 4 Percentage overlaps and counts of overlaps between pike ranges that were estimated by three methods: convex cluster polygons with outlier exclusion by truncation $\left(\mathrm{C}_{\mathrm{tx}}\right)$, kernel contours around all of the locations $\left(\mathrm{K}_{100}\right)$, and the area of channel between the maximum upstream and downstream locations (range span area)

\begin{tabular}{llrlr}
\hline & $\begin{array}{l}\text { Range } \\
\text { estimator }\end{array}$ & Median & Min Max \\
\hline Mean \% overlap & $\mathrm{K}_{100}$ & 83 & 0 & 100 \\
& $\mathrm{C}_{\mathrm{tx}}$ & 31 & 0 & 100 \\
& Range span & 100 & 0 & 100 \\
& $\quad$ area & & & \\
Number of & $\mathrm{K}_{100}$ & 3 & 0 & 9 \\
overlaps & $\mathrm{C}_{\mathrm{tx}}$ & 1 & 0 & 5 \\
& Range span & 2 & 0 & 7 \\
& area & & & \\
\hline
\end{tabular}

which had a sample size of two, was excluded $(r=0.99$, d.f. $=2, P<0.05)$.

\section{Discussion}

Manually tracking fish in the lotic environment has the potential to provide novel insights into fish behaviour and ecology, including habitat preferences, demography and territoriality. However, the collection of sufficient data to estimate home ranges can be time consuming, and hence has high associated staff costs. An intensive pilot study at the outset of a tracking project is therefore imperative to maximise the output from the effort applied, although logistical issues, such as the population distribution of the study species, and the nature of the terrain to be traversed by

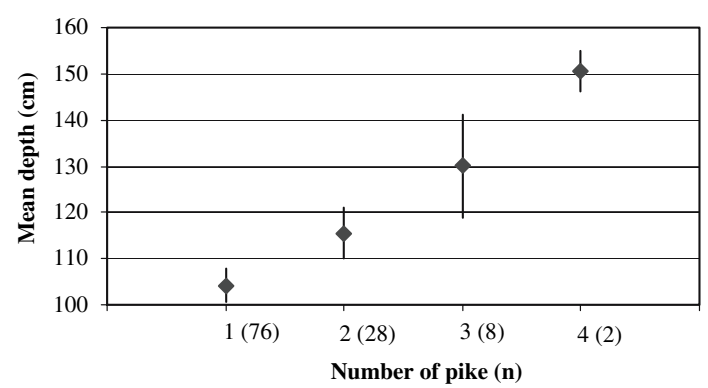

Fig. 6 The relationship between the degree of overlap between pike $C_{t x}$ core ranges, and mean ( \pm standard error) depth. On the $x$-axis, one pike indicates zero overlaps, two pike one overlap etc., and the number of records for each value is shown in brackets 
the tracker, will inevitably impose constraints on the application of tracking protocol that is developed from the pilot work.

Both the tracking protocol and the data analyses will depend on the biological questions of interest, and various logistical or statistical constraints. In this study, the kernel contours were used for comparative purposes because the pike moved out into areas beyond the river channel during floods. Despite attempts to improve area estimation by kernels through clipping off areas not within the river, there were difficulties with this technique; namely (i) expanding along the channel beyond the area utilised by the fish on straight stretches, and (ii) omitting parts of ranges in meandering stretches (Fig. 2). Although the general rule would dictate that comparisons of range areas should only be made with results obtained from the same analysis technique, in this case it may be more meaningful to compare kernel contours in floods with range span areas at other times. The cluster technique for estimating core ranges; however, was much more promising as a tool for analyses that can include linear and open systems, hence lotic and lacustrine or marine environments. It does not expand along the channel, and showed a lower tendency to expand beyond the river channel, such that there was relatively little need to correct this latter inaccuracy by clipping.

The home range analysis showed that pike in the River Frome occupied stable home ranges that could be determined over a period of two weeks with the majority of individuals spending about $90 \%$ of their time in a core range with occasional excursions. These core ranges were generally located in deeper water than the outer ranges, where the pike would presumably experience slower flows, enabling them to reduce energy requirements. This behaviour is similar to that described for lake dwelling pike, which made many localised movements and fewer long distance movements (Diana, 1980; Lucas et al., 1991).

Both outer and core ranges of individual pike in the River Frome overlapped considerably, and the degree of overlap was necessarily an underestimate, given that it was not possible to ensure that all pike in the study area were tagged. The strong positive correlation between the number of pike found in an overlap area, and the mean depth of that area, showed that pike tended to congregate in the deeper pools, although it was not possible to show whether they occupied those areas at the same time. Comparative data on range overlap were not available from other studies of pike, but Larsen (1966) recorded up to four pike of similar size within 30-40 m stretches of a Danish trout stream, and overlap of home range 'activity centres' has been reported for lake dwelling muskellunge (Miller \& Menzel, 1986). In this study, pike were also found very close together on several occasions, outside of spawning activity, even when they would have been clearly visible to one another. Ideally, analysis of dynamic interaction (Macdonald \& Amlaner, 1980; Kenward et al., 1993) could have produced a 'social cohesion index' based on proximity of individuals. However, the data were not suitable for dynamic interaction analysis because the time taken to move between individuals during each tracking round meant that the requirement for virtually simultaneous location records could not be met. Despite this, the degree of overlap between pike in the River Frome clearly showed that they did not hold exclusive territories during this study.

The great variation in range size and structure suggests that these fish exhibit the high degree of behavioural versatility that might be expected of an opportunist predator (Bry, 1996), and has also been recorded for lake-dwelling pike (Jepsen et al., 2001). Large differences also occur between studies (reviewed in Lucas \& Baras (2001)), some populations of pike in lakes occupying home ranges and others apparently ranging widely with no 'clear route'; while populations in brackish waters may display anadromous migration patterns (Muller, 1986).

Where an animal remains in a given area for sufficient time, perhaps a season or a life stage, delineation of its stable short-term home range is a useful analysis tool, which has been applied extensively in terrestrial studies over many decades (e.g. Burt, 1943). For the pike in this study, home range analysis showed that the activity of most individuals was concentrated in multinuclear core areas, situated in deeper areas 
of the channel, but that some individuals may be more mobile. When the floodplains became available to the pike, knowledge of home range structure made it possible to demonstrate that the pike expanded their core ranges, as opposed to making occasional forays into their extended habitat. The definition of range structure also provided a means to investigate and quantify the proximity of neighbouring pike and to demonstrate a lack of exclusive territories. So, despite the need for clipping of ranges, which was imposed by the linear habitat, the home range analysis techniques were able to provide quantitative insights into the behaviour and ecology of a river-fish.

Acknowledgements This work could not have been completed without the dedication of the field trackers: Chris Flower, Bethan Lewis, Neasa McDonnell, Luke Scott and Sarah Venis. John Cooper processed the depth data. We are also grateful to Mike Ladle and Stewart Welton for advice and practical help, to local landowners for allowing access to the river, and to the Environment Agency for providing river discharge data. Jerome Masters was in receipt of a Freshwater Biological Association Frost Scholarship. The manuscript was improved by incorporation of constructive comments from Eva B. Thorstad and an anonymous referee.

\section{References}

Allouche, S., A. Thevenet \& P. Gaudin, 1999. Habitat use by chub Leuciscus cephalus L. 1766 in a large river, the French Upper Rhone, as determined by radiotelemetry. Archiv fur Hydrobiologie 145: 219-236.

Baras, E., 1998. Selection of optimal positioning intervals in fish tracking: an experimental study on Barbus barbus. Hydrobiologia 372: 19-28.

Beaumont, W. R. C., B. Cresswell, K. H. Hodder, J. E. G. Masters \& J. S. Welton, 2002. A simple activity monitoring radio tag for fish. Hydrobiologia 483: 219224.

Blundell, G. M., J. A. K. Maier \& E. M. Debevec, 2001. Linear home ranges: effects of smoothing, sample size, and autocorrelation on kernel estimates. Ecological Monographs 71: 469-489.

Bry, C., 1996. Role of vegetation in the life cycle of pike. In Craig, J. F. (ed.), Pike: Biology and Exploitation. Chapman and Hall, London, 45-67.

Burt, W. H., 1943. Territoriality and home range concepts as applies to mammals. Journal of Mammalogy 24: 346-352.

Chapman, C. A. \& W. C. Mackay, 1984. Versatility in habitat use by a top aquatic predator, Esox lucius L. Journal of Fish Biology 25: 109-115.
Clough, S. \& M. Ladle, 1997. Diel migration and site fidelity in a stream-dwelling cyprinid, Leuciscus leuciscus. Journal of Fish Biology 50: 1117-1119.

Diana, J. S., 1980. Diel activity pattern and swimming speeds of Northern Pike Esox lucius in Lac Ste. Anne, Alberta. Canadian Journal of Fisheries and Aquatic Sciences 37: 1454-1459.

Dixon, K. R. \& J. A. Chapman, 1980. Harmonic mean measure of animal activity measures. Ecology 61: 1040-1044.

Doncaster, C. P. \& D. W. Macdonald, 1991. Drifting territorialty in the red fox Vulpes vulpes. Journal of Animal Ecology 60: 423-439.

Hodder, K. H., R. E. Kenward, S. S. Walls \& R. T. Clarke, 1998. Estimating core ranges: a comparison of techniques using the common buzzard Buteo buteo. Journal of Raptor Research 32: 82-89.

Huber, M. \& A. Kirchhofer, 1998. Radio telemetry as a tool to study nase Chondrostomata nasus L. in medium sized rivers. Hydrobiologia 372: 309-319.

Jepsen, N., S. Beck, C. Skov \& A. Koed, 2001. Behavior of pike (Esox lucius L.) $>50 \mathrm{~cm}$ in a turbid reservoir and in a clearwater lake. Ecology of Freshwater Fish 10: 26-34.

Jepsen, N., S. Pedersen \& E. Thorstad, 2000. Behavioural interactions between prey (trout smolts) and predators (pike and pikeperch) in an impounded river. Regulated Rivers Research \& Management 16: 189198.

Kenward, R. E., 1987. Wildlife radio tagging-equipment, field techniques and data analysis. Academic Press, London.

Kenward, R. E., 1992. Quantity versus quality: programmed collection and analysis of radio-tracking data. In Priede, I. G. \& S. M. Swift (eds), Wildlife Telemetry: Remote Monitoring and Tracking of Animals. Ellis Horwood, London, 231-244.

Kenward, R. E., 2001. A Manual for Wildlife Radio Tagging. Academic Press, London.

Kenward, R. E., R. T. Clarke, K. H. Hodder \& S. S. Walls, 2001. Density and linkage estimators of home range: nearest-neighbor clustering defines multinuclear cores. Ecology 82: 1905-1920.

Kenward, R. E. \& K. H. Hodder, 1996. RANGES V: An Analysis System for Biological Location Data. Institute of Terrestrial Ecology, Dorset, UK.

Kenward, R. E., V. Marcstrom \& M. Karlbom, 1993. Postnestling behaviour in goshawks, Accipiter gentilis: sex differences in sociality and nest switching. Animal Behaviour 46: 371-378.

Kernohan, B. J., R. A. Gitzen \& J. J. Millspaugh, 2001. Analysis of animal space use and movements. In Millspaugh, J. J. \& J. M. Marzluff (eds), Radio Tracking and Animal Populations. Academic Press, San Diego, California.

Khan, M. T., T. A. Khan \& M. E. Wilson, 2004. Habitat use and movement of river blackfish (Gadopsis marmoratus R.) in a highly modified Victorian stream, Australia. Ecology of Freshwater Fish 13: 285-293.

Larsen, K., 1966. Studies on the biology of Danish stream fishes. II. The food of Pike (Esox lucius L.) in trout 
streams. Meddelelser fra Danmarks Fiskeri- og Havundersogelser 4: 271-326.

Lucas, M. C. \& E. Baras, 2001. Migration of Freshwater Fishes. Blackwell Science Ltd, Oxford.

Lucas, M. C. \& E. Batley, 1996. Seasonal movements and behaviour of adult barbel Barbus barbus, a riverine cyprinid fish: Implications for river management. Journal of Applied Ecology 33: 1345-1358.

Lucas, M. C., I. G. Priede, J. D. Armstrong, A. N. Z. Gindy \& L. DeVera, 1991. Direct measurements of metabolism, activity and feeding behaviour of pike, Esox lucius L. in the wild, by the use of heart rate telemetry. Journal of Fish Biology 39: 325-345.

Macdonald, D. W. \& C. J. Amlaner, 1980. A practical guide to radio-tracking. In Amlaner, C. J. \& D. W. Macdonald (eds), A Handbook on Biotelemetry and Radio-Tracking. Pergamon Press, Oxford, 143-159.

Masters, J. E. G., J. S. Welton, W. R. C. Beaumont, K. H. Hodder, A. C. Pinder, R. E. Gozlan \& M. Ladle, 2002. Habitat utilisation by pike Esox lucius L. during winter floods in a southern English chalk river. Hydrobiologia 483: 185-191.

Mesing, C. \& A. Wicker, 1986. Home range, spawning migrations, and homing of radio-tagged Florida largemouth bass in two central Florida lakes. Transactions of the American Fisheries Society 115: 286295.

Miller, M. \& B. Menzel, 1986. Movements, homing and home range of muskellunge, Esox masquinongy, in West Okoboji Lake, Iowa. Environmental Biology of Fishes 16: 243-255.

Minns, C. K., 1996. Allometry of home range size in lake and river fish. Canadian Journal of Fisheries and Aquatic Sciences 52: 1499-1508.

Mohr, C. O., 1947. Table of equivalent populations of North American small mammals. American Midland Naturalist 37: 223-249.
Muller, K., 1986. Seasonal anadromous migration of the pike (Esox lucius L.) in coastal areas of the northern Bothnian sea. Archiv fur Hydrobiologie 107: 315-330.

Natsumeda, T., 1998. Home range of the Japanese fluvial sculpin Cottus pollux in relation to nocturnal activity patterns. Environmental Biology of Fishes 53: 295301.

Ovidio, M., E. Baras, D. Goffaux, F. Giroux \& J. C. Philippart, 2002. Seasonal variations of activity pattern of brown trout (Salmo trutta) in a small stream, as determined by radio-telemetry. Hydrobiologia 470: 195-202.

Ovidio, M., J. C. Philippart \& E. Baras, 2000. Methodological bias in home range and mobility estimates when locating radio-tagged trout, Salmo trutta, at different time intervals. Aquatic Living Resources 13: 449-454.

Snedden, G. A., W. E. Kelso \& D. A. Rutherford, 1999. Diel and seasonal patterns of spotted gar movement and habitat use in the lower Atchafalaya River Basin, Louisiana. Transactions of the American Fisheries Society 128: 144-154.

Swihart, R. \& N. Slade, 1985. Testing for independence of observations in animal movements. Ecology 66: 11761184.

Vokoun, J. C., 2003. Kernel density estimates of linear home ranges for stream fishes: advantages and data requirements. North American Journal of Fisheries Management 23: 1020-1029.

White, G. C. \& R. A. Garrot, 1990. Analysis of Wildlife Radio Tracking Data. Academic Press, San Diego.

Worton, B. J., 1987. A review of some models of home range for animal movement. Ecological Modelling 38: 277-298.

Worton, B. J., 1989. Kernel methods for estimating the utilisation distribution in home range studies. Ecology 70: 164-168. 